DOI 10.37882/2223-2982.2022.01.27

\title{
КОЧЕВОЙ ЛАГЕРЬ: ПРОШЛОЕ И НАСТОЯЩЕЕ 1
}

\section{NOMAD CAMP: PAST AND PRESENT \\ Yu. Sleptsov}

Summary: The article examines the process of introducing a model of the activity of a nomadic camp during the summer holidays for children of the indigenous small peoples of the North - the Evens - in the Republic of Sakha (Yakutia) in order to preserve the traditional way of life and teach their native language. Work experience from 2000 to 2021 showed that a similar model of the camp can be applied by all peoples leading a nomadic lifestyle. A nomad camp is an innovative form of a temporary cultural and educational social institution. During the work, methods and technologies of folk pedagogy were used, through which children studied their native Even language and culture, immersed themselves in authentic forms of life and traditional types of management: domestic reindeer husbandry, hunting and fishing, national sewing, as well as customs and rituals, folk dances, etc. games. Pupils of the nomad camp successfully work in various sectors of the national economy, including teachers of their native language and national culture. Many specialists were interested in the experience of the temporary children's association, for example, scientists from the United States of America, who developed the «Reindeer Mapper» project. Many regions of the Russian Federation have introduced summer camps in accordance with their requirements and capabilities.

Keywords: indigenous peoples of the North, Evens, school-age children, nomadic camp, traditional education, model, ethnopedagogization, community society.
Слепцов Юрий Алексеевич

К.п.н., м.н.с., Институт гуманитарных исследований и проблем малочисленных народов Севера СО РАН, г. Якутск seva_may@mail.ru

Аннотация: В статье рассматривается процесс внедрения модели деятельности кочевого лагеря в период летних каникул для детей коренных малочисленных народов Севера - эвенов - в Республике Саха (Якутия) в целях сохранения традиционного уклада жизни и обучения родному языку. Опыт работы с 2000 по 2021 гг. показал, что подобная модель лагеря может быть применена всеми народами, ведущими кочевой образ жизни. Кочевой лагерь - инновационная форма временного культурно-образовательного социального института. Во время работы применялись методы и технологии народной педагогики, посредством которых дети изучали родной эвенский язык и культуру, погружались в аутентичные формы жизнедеятельности и традиционные виды хозяйствования: домашнее оленеводство, охотничий промысел и рыболовство, национальные шитье, а также обычаи и обряды, народные танцы и игры. Воспитанники кочевого лагеря успешно работают в различных отраслях народного хозяйства, В том числе и педагогами родного языка и национальной культуры. Опытом работы временного детского объединения интересовались многие специалисты, к примеру, ученые из Соединенных Штатов Америки, которые разработали проект «Олений след». Многие регионы Российской Федерации внедрили летние лагеря в соответствии со своими требованиями и возможностями.

Ключевые слова: коренные малочисленные народы Севера, эвены, дети школьного возраста, кочевой лагерь, традиционное воспитание, модель, этнопедагогизация, общинный социум.

\section{Ввецение}

$\Pi$ ервый кочевой лагерь «Нелтэнкэ» был организован летом 2000 г. на базе оленеводческой бригады «Чолой» Момского района Республики Саха (Якутия) и проработал в данном месте два года. В 2001 г. был открыт кочевой экологический лагерь «Маранга». Воспитанники лагеря в свободное от повседневного оленеводческого труда время исследовали обширную площадь своего родного края, где они на практике изучали экологию, топонимику, собирали гербарий, послужившие эффективным учебным материалом для освоения лингвокультурного наследия предков.

Как известно, время - главный критерий эффективности работы [6, с.172]. К примеру, из 12-ти детей, участвовавших в работе лагеря «Маранга», 8 воспитанников впоследствии стали дипломированными педагогами различного профессионального направления, использующими в своей деятельности родной эвенский язык и этнокультурные традиции.

В 2002 г. был организован кочевой лагерь «Гарпанга» при Улахан-Чистайской средней общеобразовательной школе. Данный лагерь работает по настоящее время. В рамках реализации проекта гранта № 21-2-005539 «Образование временных детских объединений в местах кочевий во время летних каникул» фонда Президентских грантов Российской Федерации была организована работа двух сезонов кочевого лагеря: первый - в оленеводческой бригаде родовой общины им. С.Г. Слепцова, а второй - на территории ООПТ «Момский национальный природный парк», возле озера «Улахан-Кюель».

1 Статья подготовлена при поддержке гранта Президентского фонда № 21-2-005539 


\section{Основная часть}

Кочевой лагерь - новая форма организации временного коллектива для воспитания детей с погружением в традиционную хозяйственную деятельность, языковую и культурную среду коренных малочисленных народов. В настоящее время в Республике Саха (Якутия) функционируют различные типы кочевых школ: кочевая школа - детский сад; общинная школа в местах компактного проживания коренных народов Севера; тундровая, лесотундровая, таежная кочевые школы - филиалы базовых средних школ; стационарно-кочевая школа (учащиеся в определенный срок выезжают в оленеводческое стадо); сетевая кочевая школа (передвигается между несколькими стадами по очно-заочной форме обучения).

Цель кочевого лагеря - создание мобильной системы кочевого образования с целью обеспечения доступности и всеобуча для детей коренных малочисленных народов Севера в условиях кочевого и полукочевого образов жизни и ведения традиционных видов хозяйствования $[9$, с.16].

Одним из мотивов организации кочевого лагеря явилось то, что в 50-60-е годы XX в. произошли события, которые существенным образом повлияли на жизнь и деятельность коренных малочисленных народов Севера. В результате непродуманной политики насильственного перевода в оседлый уклад жизни народов, ведущих исконно кочевой образ жизни, была прервана преемственность поколений по традиционному народному воспитанию детей. По итогам Всероссийской переписи населения 2010 года, в Российской Федерации проживают 22383 эвенов (ламутов), из них владеют родным языком 5538 чел., т.е. 25\% [8, с. 89]. Подобная динамика наблюдается и у других коренных малочисленных народов Севера Якутии: долган, эвенков, чукчей, юкагиров.

Предпосылки создания кочевого лагеря:

- Дети, которые живут в интернатах в отрыве от своих кочующих родителей-оленеводов, растут оторванными от традиционного стиля жизни, что в результате ведет к утрачиванию знаний, обычаев и всего культурного наследия своего народа;

- Резкое понижение знания и употребления родных языков (одна из задач лагеря: освоение детьми родного эвенского языка);

- Утрата навыков по ведению оленеводства и традиционного труда оленеводов.

Учитывая вышеперечисленное, для достижения указанной цели кочевого лагеря были предприняты следующие практические шаги:

1. В сфере родного языка:

1.1. Обучение детей родному эвенскому языку в естественной среде окружения;
1.2. Изучение местных топонимов, названий растительности в их связи с коренным языком эвенов.

2. В социально-культурной сфере:

2.1. Погружение нового поколения детей эвенов в традиционный общинный стиль жизни и исконные занятия их предков оленеводов;

2.2. Практическое приобщение детей к труду оленеводов, к традиционным знаниям, умениям и владениям, обычаям охотничьего и рыболовного промыслов.

3. В сфере экологического знания:

3.1. Изучение естественной среды обитания оленеводов [7, с.28].

В ходе культурно-образовательного процесса педагогическим коллективом воспитателей и наставников применялись, с одной стороны, критерии для характеристики общего личностного развития детей (мотивы пребывания в кочевом лагере, семейное положение, активная и сознательная деятельность, увлечения, достижения), с другой стороны, проводилось непрерывное наблюдение, фиксирование, корректирование воспитателями и наставниками тех или иных фактов и явлений в процессе деятельности воспитанников, характеризующих их традиционную этническую идентичность (усвоение знаний, умений и навыков по языку, культуре, традиционным отраслям хозяйства родного народа, готовность применять их на практике; соблюдение этнических традиций предков: морально-этических принципов, норм, правил и заповедей, уважение и послушание старших, родителей и т.д.) [5, с.32].

Были созданы организационно-педагогические условия с этнической направленностью содержания, форм и методов, обусловленные спецификой деятельности кочевого лагеря в условиях Севера, как новой формы организации традиционного этнического воспитания детей коренных малочисленных народов Севера:

- формирование разновозрастного объединения учащихся из числа коренных малочисленных народов Севера;

- практическая деятельность детей в естественных природно-климатических условиях Якутии, в целом Севера (в местах кочевания предков, занимавшихся домашним оленеводством и т.д.);

- искусственное создание атмосферы непринужденного общения учащихся в процессе деятельности лагеря по всем направлениям комплексной программы по традиционному воспитанию при педагогическом сопровождении воспитателей и наставников - опытных оленеводов, мастеров народного творчества, старейшин, т.е. носителей эвенского языка и культуры;

- во время длительных летних каникул (июнь-август) детям предоставляется возможность погружаться в самобытную кочевую жизнь и де- 
ятельность, языковую среду, что обеспечивает результативность и действенность образовательно-воспитательного процесса.

Необходимо отдельно отметить роль национальных игр. Разнообразие народных игр у эвенов описано первыми русскими землепроходцами. Например, Я.И. Линденау в своем труде отмечает игры с применением мяча, различные гонки, борьбу и т.п. [2, с. 63]. Многие из этих игр современные дети не знают. В кочевом лагере активно используется весь арсенал игр, где ребята впервые знакомятся с премудростями национальных игр. Как справедливо отметила в свое время Маргарет Мид, игры детей напоминают игры взрослых по своему характеру, интересу, ими вызываемому, и по их взаимоотношению с трудом [3, с.169].

Особую роль в изучении родного языка имеет топонимика родного края. Каждая местность в УлаханЧистайском наслеге кроме якутского названия имеет и эвенское. Каждая из них обладает своей легендой или мифологической основой. К примеру, проходя мимо реки Киникич (с эвенского «вода, выходящая из-под земли»), дети из рассказов наставника узнают, что в этой местности поспорили два шамана и, что река выходит из-под земли, а иногда, несмотря на ясную погоду, может нагрянуть гроза с молнией $[1$, с. 9]. Дети легко запоминают название тех мест, где проходит маршрут передвижения кочевого лагеря. Дети не только усваивают смысл названия, но и узнают небезопасные для жизни людей и оленей места.

Опыт работы кочевого лагеря можно применить в любых условиях. Для этого не обязательно постоянно передвигаться, можно организовать все в стационарном лагере, где дети получат возможность изучить родной язык и культуру. Первое условие кочевого лагеря - это удаленность от населенного пункта. Дети должны быть искусственно отдалены от цивилизации. Это обеспечивает сосредоточение ребенка на процессе повседневного труда оленевода. Воспитанники кочевого лагеря «Гарпанга», которые пребывали в 2002 г., при встрече всегда отмечают, что они во время пребывания в лагере научились труду в экстремальных кочевых условиях.

Работа кочевого лагеря в 2021 г. была профинансирована фондом Президентских грантов, что дало возможность экспериментировать. Так, первый сезон дети работали в оленеводческой бригаде родовой общины им. С.Г. Слепцова, где дети с помощью опытных наставников обучались верховой езде, навыкам работы в оленеводстве. Часть ребят, в основном старшеклассники, изъявили работать в бригаде и остались до открытия школы. Второй сезон был открыт на территории особо охраняемой природной территории «Момский нацио- нальный природный парк» в окрестностях озера «Улахан Кюель». Дети обучались навыкам рыболовства - одного из традиционных видов хозяйствования коренных малочисленных народов - эвенов. Кроме этого, с детьми проводилось экологическое просвещение. Озеро «Улахан-Кюель» - одно из уникальных природных мест, оно не замерзает зимой даже при $-60^{\circ} \mathrm{C}$. Здесь зимуют перелетные птицы: утки, гуси, лебеди, которые по разным причинам не смогли перелететь в теплые страны.

Как и в предыдущие годы, в кочевом лагере в основном участвуют дети из социально-неблагополучных семей (проблема алкоголизма), из неполных (один родитель) и многодетных семей. В сезон в 2021 г. все дети были из многодетных семей, 40\% - из неполных. Социальная проблема неполных семей в Арктике стоит остро, основная причина - алкоголизм. Поэтому в лагере упор делается на здоровый образ жизни. Как показывает практика, некоторые родители, которые видят позитивный результат работы лагеря и его положительное влияние на ребенка, отказываются от алкоголя. Многие воспитанники вспоминают: «Если бы Юрий Алексеевич нас не обучал и не воспитывал в кочевом лагере, мы бы возможно стали либо алкоголиками, либо нас уже не было бы». Безусловно, этот результат не 100\%. Многие дети, несмотря на предпринятые усилия, выбрали другой путь, и итог их жизни весьма печален. Именно это факт мы применяем при воспитании как отрицательный символ. Отрицательные символы - образы таких людей, которые, согласно доминирующей точке зрения, в своей деятельности наносили этносу большой вред [4, с.159].

\section{Зак^ючение}

В последние годы интерес к проблемам Севера возрастает во многих научных дисциплинах. Многие ученые отмечают, что жизненные условия изучаемых народов значительно ухудшились в последние 15-20 лет. Самое трагичное, что может произойти с коренными северными народами, это то, что их язык, история, традиционный уклад жизни могут исчезнуть навсегда. Миссия современного поколения заключается в том, чтобы жизнь на Севере продолжалась в своем традиционном ритме и темпе. Перед нами стоит задача: сохранить самобытную культуру, родной язык, традиционные виды хозяйствования и образ жизни. Одним из способов решения данной задачи является организация кочевого лагеря. Таким образом, мы видим, что деятельность кочевого лагеря приводит к положительному результату в традиционном воспитании подрастающего поколения коренных народов Севера и может быть применен многими этносами, что даст возможность сохранения самобытной культуры малочисленных народов Севера, Сибири и Дальнего Востока. 


\section{ЛИТЕРАТУРА}

1. Дегтярев А.М. По родным местам... (Топонимика Момского улуса) / А.М. Дегтярев, Р.Г. Дегтярева, Ю.А. Слепцов. - Якутск: Изд-во Якутского ун-та, 2005. $-32 c$.

2. Линденау Я.И. Описание народов Сибири (первая половина XVIII века): историко-этнограф. материалы о народах Сибири и Северо_Востока. / Я.И. Линденау. - Магадан: Кн. изд-во, 1983. - 176 с.

3. Мид М. Культура и мир детства / М. Мид. - М.: Наука, 1988. - 429 С.

4. Налчаджян А.А. Этнопсихология. 2-е изд. / А.А. Налчаджян - СПб.: Питер, 2004. - 381 с: ил.

5. Неустроев Н.Д. Традиционное воспитание детей малочисленных народов Севера - эвенов в условиях кочевого лагеря // Н.Д. Неустроев, Ю.А. Слепцов / Педагогика и просвещение. - 2018. - № 2. - С. 31 - 37.

6. Подласый И.П. Продуктивная педагогика: Книга для учителя. / И.П. Подласый. - М.: Народное образование, 2003. - 496 с.

7. Слепцов Ю.А. Этнопедагогические традиции воспитания детей эвенов / Ю.А. Слепцов // Наука и образование. 2010. №4. - С. 27-29.

8. Социально-демографический портрет России: По итогам Всероссийской переписи населения 2010 года / Федер. служба гос. статистики. - М.: ИИЦ «Статистика России», 2012. - 183 с.

9. Слепцов Ю.А. Педагогические особенности организации традиционного воспитания детей коренных малочисленных народов Севера в кочевом лагере: дис. канд. пед. наук: 13.00.01 / Слепцов Юрий Алексеевич; - Якутск, СВФУ им М.Аммосова, 2018. - 221 с.

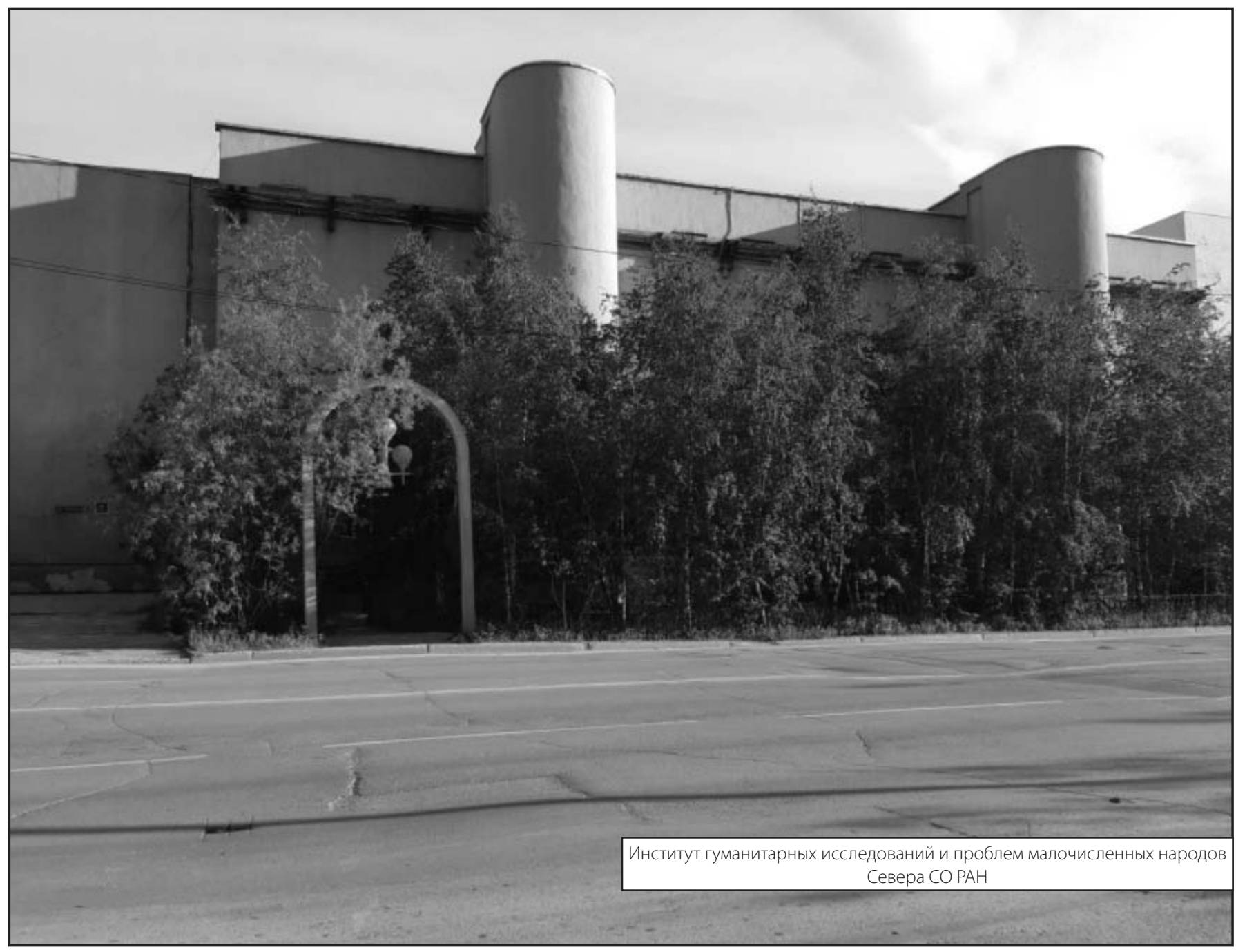

